\title{
A Review of Peer Tutoring Interventions and Social Interdependence Characteristics
}

\author{
Mirjan Zeneli, Peter Tymms \\ Durham University, $U K$
}

\begin{abstract}
Peer tutoring is a form of peer learning proven to be an effective educational intervention in terms of improving students' performance, social and academic attitudes, behaviour and language. Social Interdependence Theory provides a broad framework for understanding peer learning effectiveness. Although the framework has been widely applied in groups of three or more students, it is unclear to what extent the framework has been applied in a peer tutoring context. Consequently, it is not known whether peer tutoring interventions are making use of social interdependence elements shown to yield high effect sizes. The research objectives for this paper are therefore to: I) explore the extent to which peer tutoring interventions have taken a social interdependence perspective while implemented, II) identify the academic subjects with most social interdependence theoretical elements and III) explore the most/least frequent social interdependence elements applied to peer tutoring. Eleven established social interdependence ideas/elements were identified and used to scan 127 articles with 252 peer tutoring interventions. The aim is for the findings to contribute to the improvement of peer tutoring interventions for teachers and academics by identifying opportunities for more work.
\end{abstract}

\section{Introduction}

A recent review of the 'what works literature' in education research by Higgins, Katsipataki, Coleman, Henderson, Major and Coe [7] revealed that three of the most effective interventions in education, in terms of cost effectiveness and being properly evidenced, are effective feedback that is personalised and elaborated on, (eight months in academic gains), meta-cognition (eight months in academic gains) and peer tutoring (six months in academic gains). To understand why and how peer tutoring yields a high positive impact it is important to note that many peer tutoring interventions by their nature encompass both personalised and rapid feedback as well as a context for meta-cognition.

The aim of this study is to review the extent to which peer tutoring studies, implicitly or explicitly, take a social interdependence perspective in areas of literacy, mathematics and science for students between four and eighteen years of age. It will follow three steps: first, identifying some of the main social interdependence elements usually promoted in peer learning in general; second, conducting a methodological review of past peer tutoring interventions to identify peer tutoring studies; and finally, scanning the peer tutoring papers using the social interdependence benchmarks to then analyse the data.

Peer tutoring has been defined in many ways, the most informative of which being that of Topping and Ehly [17] who provide a typology of different peerassisted learning techniques. Generally defined peer tutoring is a condition whereby one or many students tutor one or many other students in an academic subject by acting as a mentor and providing hints, questions and instructional guidance. The authors differentiate the method from other peer assisted learning methods such as 'Peer Facilitation and Education', which incorporates elements including 'Peer Modelling', 'Peer Education for Health' and 'Peer Counselling', and 'Peer Feedback', which concentrates only on 'Peer Assessment' and 'Peer Monitoring'.

According to Topping and Ehly [17], peer tutoring can involve students of the same age from the same class, or older students tutoring younger students with an age gap of two to three years; while cross-age tutoring always also crosses ability, sameage tutoring may also cross abilities, and can be fixed-role or reciprocal tutoring. At the heart of Social Interdependence Theory is the role of interdependence between students [1]. According to Chambers [2], this can be achieved in various ways: positive interdependence, task interdependence, role interdependence, outside force interdependence, reward interdependence and individual accountability.

However, Social Interdependence Theory also encompasses elements from other peer learning theories. Specifically, it highlights the importance of social skills training, praising and set roles, which are emphasised by Social Skills and Role Theories; the importance of intrinsic motivation and autonomy, as identified by Self Determination Theory; and the importance of academic training, working with advanced cognitive and meta-cognitive materials or 
cross-ability groupings, all of which lie at the heart of Social Constructivism.

Hence, the Social Interdependence paradigm is a broad and complex framework that aims to raise social and academic processes of learning elements simultaneously, two elements usually lacking in lowperforming classrooms in which many peer tutoring interventions have been implemented. Although there is a general consensus that students require less social skills training to work in smaller group sizes since the communication dynamics are less complex, Social Interdependence Theory maintains that some form of social skills training is a prerequisite for students to move on to more complex academic interactions.

\section{Literature Review}

Previous literature reviews of peer tutoring have largely concentrated on identifying what works within peer tutoring, and have mostly taken the form of meta-analyses [4] [6] [11] [13] [14]. They have shown that social interdependence elements have provided higher effect sizes for students' achievements and the process of learning elements. Specifically, the earliest meta-analysis by Cohen, Kulik and Kulik [4] revealed that cross-age peer tutoring interventions, which by nature involve cross-ability pairing and set roles - two key elements emphasised by social interdependence advocates yield large effect sizes. The meta-analysis found that cross-age tutoring had a larger mean effect size .42 than same-age peer tutoring .29 , as did trained students mean effect size .38 vs. untrained students .34. A more recent meta-analysis by Rohrbeck, Ginsburg-Block, Fantuzzo and Miller [13] also found that cross-age tutoring provides a larger mean effect size .80 than same-age peer tutoring .47 , as did reward and goal interdependent elements as set by students, mean effect size .99 and .89 respectively, vs. goals and rewards as set by teachers, which had a mean effect size of .30 for both.

Similar findings for the above variables, especially for autonomous structural elements that give the choice to the students, have been shown for the impact of peer tutoring or groups of three for the process of learning elements such as self-concepts and behaviour [6].

To date, no study has investigated the extent to which peer tutoring interventions have taken a social interdependent position encompassing some of the above elements. The few meta-analytical studies that have reported the frequency of some of the above elements have included only quantitative papers; hence, there is no overall picture.

\section{Research Questions}

There are three main research questions in this study, which derive from the main research aim:

A. To what degree have peer tutoring interventions applied a broad social interdependence position?

B. In which of the core academic subjects has previous research implemented most social interdependence elements?

C. What social interdependence elements have been most/least frequently implementing in peer tutoring interventions in core academic subjects?

Consequently, the significance of this review is that it is the first to provide a reflection/evaluation of the degree to which teachers and researchers have taken a social interdependence approach when implementing peer tutoring. It will also identify the social interdependence theoretical elements and core academic subjects that need more attention in terms of future research for teachers, researchers and policy makers.

\section{Method}

\subsection{Procedures}

The search was mainly conducted using three online databases: PsycINFO, ERIC (Education Resources Information Centre) and ProQuest Dissertations. The first two engines are considered robust search databases for reviews [12].

The following terms were used to search the databases: "peer tutoring", "peer learning", "paired learning", "cooperative learning", "cross-age peer learning", "reciprocal peer learning", "peer-assisted learning" and "PAL". The search included all papers, i.e. books and journals. The searched age group was four to eighteen, and the published language was English.

PsycINFO produced 18,623 results, ERIC produced 6,704 and ProQuest Dissertation produced 1,345. Other important hand-picked journals were the British Journal of Educational Psychology and The Journal of Educational Psychology. Studies included in books and academic conferences were also included.

Out of over 26,000 related publications that emerged online, a lengthy manual effort reduced the number to only 652 qualified studies related to peer learning. Of those, 305 were reviews, comments, group learning between more than two students, etc. Consequently, 347 articles entered the inclusion criteria screening stage. 


\subsection{Inclusion criteria}

There were no restrictions in terms of the research methodology applied in each study, since the aim was not to conduct a meta-analysis. Thus, both qualitative and quantitative papers were included. Many of the inclusion criteria, therefore, reflected the research questions:

I. Quality of studies: To include only published work, journal articles, books or book chapters and conference papers. This meant the studies had undergone some form of reviewing, which of course might create a publication bias.

II. Timescale of publications: Publications covering the years 1965-2013, as previous metaanalyses have shown that few peer tutoring interventions were conducted prior to 1965 .

III. Subjects: Only studies including peer tutoring in academic subjects entered the analysis. The studies had to concentrate on literacy, mathematics or science.

IV. Language: The studies had to be in English. This element might also introduce some publication bias.

V. Age: Only studies researching ages four to eighteen were included. Despite setting the search engines to exclude ages under four or over eighteen, some studies outside this age range still appeared.

VI. Other population characteristics: Studies involving only students with learning disabilities were excluded. This was because many peer tutoring studies conducted with students with disabilities incorporate hard-to-follow terminology, and many of the interventions have taken place in experimentallike situations outside the classroom context.

VII. Nature of the interactions: Peer tutoring had to have taken place face-to-face and in the school setting, thus excluding online, community or homebased interventions.

VIII. Length of the interventions: The studies had to be conducted over more than one session. Studies conducted for only one session were not classified as interventions since for most peer tutoring interventions the first lesson is more of a training experience for the tutor and tutee rather than learning or teaching.

It must be pointed out that the inclusion criteria above probably introduced some form of publication bias, especially the criteria for the quality of studies and language. Of the 347 articles, 127 passed all the criteria. Most of the studies that did not pass the inclusion criteria stage involved a special-education population (38 articles).

\subsection{Social interdependence elements}

This section identifies the benchmarks used when screening the articles. Each article was investigated according to the following eleven theoretical benchmarks derived from various aspects of Social Interdependence Theory [3] [8] [9] [10] [15] [16]:

I. Reward interdependence: For a tutoring condition to be classified as implementing reward interdependence the reward needed to be positively structured, i.e. students within each pair depended on each other in order to achieve the reward. Most of the studies with these characteristics involve sameage reciprocal peer tutoring interventions.

II. Goal performance interdependence: The pairs needed to be positively structured, i.e. in such a way that in order for the students to meet their goal they had to help each other. Similarly, studies with goal performance interdependence are of the same-age peer tutoring nature, mostly conducted in the USA.

III. Set roles interdependence: The students in pairs needed to have set, non-reciprocal, roles, unless the reciprocity took place after a period of six weeks, which is usually long enough for a role to sink in. Role interdependence is a crucial element in terms of entrusting students with responsibility and making them feel valued, as well as clarifying the boundaries and students' roles.

IV. Interpersonal communication skills training: The students had to undergo at least thirty minutes of social skills training. Communication skills training is also considered a crucial characteristic according to the social interdependence perspective, as it is the basis for effective interactions and influences the nature of all subsequent discourse. The main idea behind this element is that positive communication skills would provide a form of interdependence between the tutor and the tutee, as they trigger contagious emotions.

V. Informative social script/guidance interdependence: This refers to the idea of providing some form of guidance for students' academic interactions. At least two of the following elements needed to be included in order for a study to be classified as possessing informative script interdependence, reminding students of: a) their role, b) their goal, c) their reward, d) to use positive communication skills and e) praising.

VI. Interdependence via praising: For a study to be seen as using praise, it needed to mention that it had trained or encouraged students to praise each other while working in pairs. Praise is viewed not only as a feedback mechanism but also as a stimulation mechanism effecting students' motivation, and as a form of interpersonal communication skill.

VII. Cross ability: Tutee and tutor needed to differ in their academic ability. Papers codified with cross ability were: a) those which were of cross age, b) same-age studies that differed in terms of ability within the subject matter in which peer tutoring took place and c) papers in which the students were of same/similar ability but where the researchers had 
manipulated the context via artificial means such as flash cards with answers on the back.

VIII. Academic skills training: The students needed to have been taught how to make use of the peer tutoring materials and when and how to ask questions or give explanations and feedback. This could have taken place via role-play, demonstrations or explanations.

IX. Advanced-deep/cognition: The studies had to include any of the following to be classified as implementing a peer tutoring intervention with advanced cognitive strategies: a) elaborative conceptual questioning, b) elaborative answers and explanations, c) predictive strategies and d) knowledge transformation, i.e. applications of learned knowledge to real life.

X. Meta-cognition: Peer tutoring interventions classified as using meta-cognition needed to have students using any of the following: a) proposition questions, b) summarising/reviewing their learned knowledge and c) linking new concepts to previously learned concepts or categorising ideas.

XI. Academic script/guidance interdependence: This also refers to resource interdependence, without which students would not be able to work together. Studies needed to include scripts with at least two of the following: a) flash cards, b) deep/elaborative cognitive strategies, c) meta-cognitive strategies, d) when and how to ask or answer questions, e) when to give feedback and f) when to praise.

\section{Findings}

Table 1 shows the mean of theoretical elements for each academic subject, as well as the overall mean of social interdependence theoretical elements for all core academic subjects.

Table 2 presents the percentages of each theoretical element applied to literacy, mathematics and science, together with some other details.

Table 3 shows the coding method.

Figure 1 shows the number of theoretical elements for the three domains. The following are the findings:

Findings for Question A - 'To what degree have peered tutoring interventions applied a broad social interdependence position?':

Figure 1 shows that up to 43 interventions contained 1-2 elements, 81 interventions 3-4, 71 interventions 5-6 and 45 interventions 7-8 elements. Six interventions involved no theoretical elements, and no intervention consisted of more than eight theoretical elements.

The overall mean was 4.38 theoretical elements (Std. 2.01, N=252) per study.

Findings for Question B - 'In which of the core academic subjects have researchers implemented most social interdependence elements?':
Table 1 shows that literacy had the highest mean of 4.92 (Std. 1.73, N=139) theoretical elements, followed by science 3.88 (Std. 2.09, N=32) and mathematics 3.65 (Std. 217, N=81).

Table 1. Peer tutoring elements by subject

\begin{tabular}{|l|l|l|l|l|}
\hline & Mean & S.D. & $n$ & Studies \\
\hline Literacy & 4.92 & 1.73 & 139 & 82 \\
\hline Mathematics & 3.65 & 2.17 & 81 & 43 \\
\hline Science & 3.88 & 2.09 & 32 & 14 \\
\hline Total & 4.38 & 2.01 & 252 & $139 *$ \\
\hline
\end{tabular}

* Of the 127 articles, 10 concentrated on more than one academic area, giving a total of 139 studies and 252 peer tutoring interventions.

Also, most peer tutoring studies were conducted in literacy (82 studies, 139 interventions), followed by mathematics (43 studies, 81 interventions) and then science (14 studies, 32 interventions).

Findings for Question C - 'What social interdependence elements have been most/least frequently implemented in peer tutoring interventions in core academic subjects?':

Three of the most commonly applied theoretical elements were:

First, 'academic skill training', with $93 \%$ of all science interventions having trained students in academic skills, then literacy with $84 \%$ and mathematics with $81 \%$ of the papers.

Second, 'cross ability'; up to $78 \%$ of all papers relating to literacy contained some form of cross ability between the students, followed by mathematics $55 \%$ and science $48 \%$.

Third, 'role interdependence', with $63 \%$ of the papers in literacy having students with fixed roles, $48 \%$ for mathematics and $45 \%$ for science.

The areas where less attention has been given when implementing peer tutoring were:

First, 'social script interdependence'; none of the papers in science contained any form of social script interdependence to guide students' social communication skills, $19 \%$ of the papers in mathematics had some form of social script interdependence and $31 \%$ of the papers in literacy did so.

Second, 'reward interdependence'; only $10 \%$ of the science papers had some form of reward interdependence, compared to $25 \%$ of papers in mathematics and $30 \%$ of papers in literacy.

Third, 'goal setting interdependence'; $10 \%$ of all papers in science contained some form of goal setting; for literacy and mathematics this percentage was $29 \%$ and $30 \%$ respectively.

Fourth, 'social communication skills training'; $13 \%$ of papers in mathematics reported having trained students in social communication skills prior 


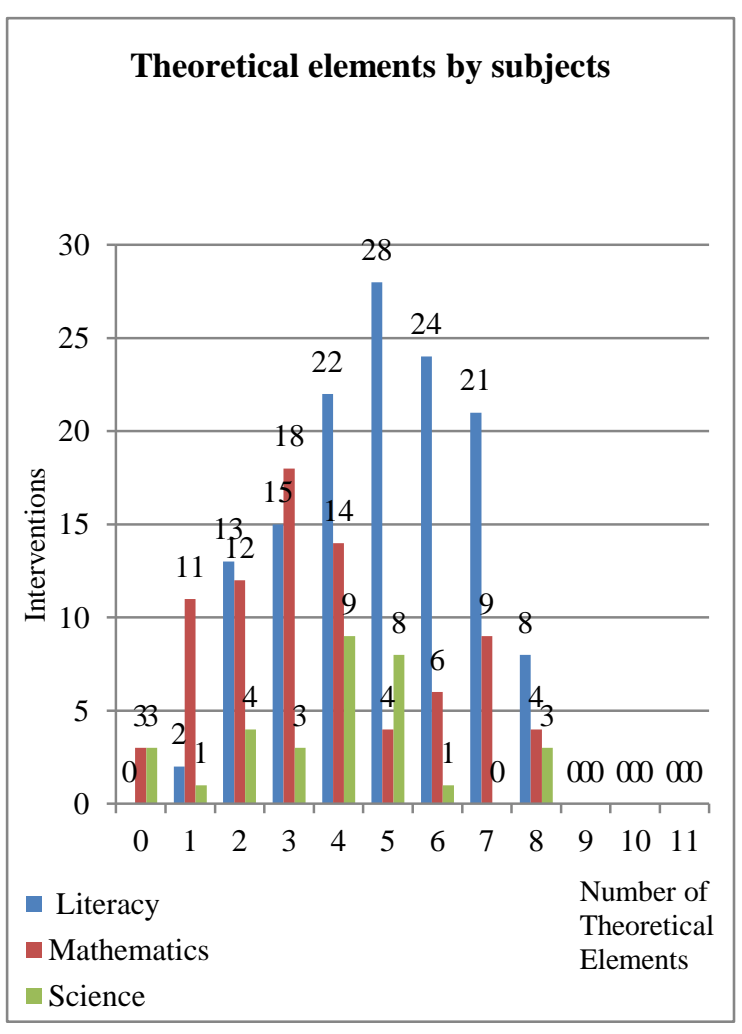

Figure 1. Interventions and theoretical elements in peer tutoring

Table 2. Percentage of theoretical elements

\begin{tabular}{|c|c|c|c|}
\hline \multirow[b]{2}{*}{$\begin{array}{l}\text { Theoretical } \\
\text { Elements }\end{array}$} & \multicolumn{2}{|c|}{ Subjects \% } & \multirow[b]{2}{*}{$\begin{array}{c}\text { Science } \\
14 \\
\text { Studies }\end{array}$} \\
\hline & $\begin{array}{c}\text { Literacy } \\
82 \\
\text { Studies }\end{array}$ & $\begin{array}{c}\text { Math } \\
43 \\
\text { Studies }\end{array}$ & \\
\hline $\begin{array}{l}\text { 1. Reward } \\
\text { Incentives }\end{array}$ & 30 & 26 & 10 \\
\hline 2. Goal Setting & 30 & 29 & 10 \\
\hline $\begin{array}{l}\text { 3. Fixed } \\
\text { Roles }\end{array}$ & 63 & 48 & 45 \\
\hline $\begin{array}{l}\text { 4. Cross } \\
\text { Ability }\end{array}$ & 78 & 55 & 48 \\
\hline $\begin{array}{l}\text { 5. Social } \\
\text { Script }\end{array}$ & 31 & 19 & 0 \\
\hline $\begin{array}{l}\text { 6. Academic } \\
\text { Script }\end{array}$ & 63 & 29 & 48 \\
\hline 7. Praise & 48 & 39 & 24 \\
\hline $\begin{array}{l}\text { 8. Academic } \\
\text { Training }\end{array}$ & 84 & 81 & 93 \\
\hline $\begin{array}{l}\text { 9. Social } \\
\text { Skills } \\
\text { Training }\end{array}$ & 14 & 13 & 55 \\
\hline $\begin{array}{l}\text { 10. Elaborative } \\
\text { Cognition }\end{array}$ & 26 & 28 & 55 \\
\hline $\begin{array}{l}\text { 11. Meta- } \\
\text { Cognition }\end{array}$ & 24 & 19 & 38 \\
\hline
\end{tabular}

to peer tutoring interventions, for literacy the number was $14 \%$, and for science the percentage was higher at $55 \%$.
Finally, 'meta-cognition'; in terms of papers explicitly incorporating meta-cognitive activities, $19 \%$ of the studies in mathematics did so, compared to $24 \%$ for literacy and $38 \%$ for science.

In eight out of eleven theoretical elements, literacy had the largest application of theoretical elements; in other words, peer tutoring papers in literacy made more use of social interdependent elements than those focusing on mathematics or science.

\section{Limitations of this study}

The main limitation of this study is that it incorporates a publication bias derived mainly from concentrating on published work in English. Therefore, the findings can only be generalised to the English-speaking population and to those without special needs, where it does provide some clear indications of what has been investigated.

Another limitation of the review is that it does not further code-specific theoretical elements such as goals and rewards as set by students, and goals and rewards set by the teachers or researchers.

Finally, it would also be interesting to see how the theoretical elements applied here reflect on other academic areas related to arts, or on different population characteristics. Such investigation would provide an even broader picture and further help teachers and researchers in exploring different forms of peer tutoring.

\section{Discussion}

The findings suggest that most peer tutoring interventions reviewed in this study have not implemented a broader social interdependence framework. This was especially the case for mathematics and science.

A broad theoretical implementation of peer tutoring, such as Social Interdependence Theory, is not necessary for the success of peer tutoring interventions; as Yarrow and Topping suggest, what is crucial is that the intervention is the correct one for the students' needs [18].

On the other hand, young students often need to master both social and academic skills; hence, implementing a peer tutoring model influenced by Social Interdependence Theory to its fullest degree should be beneficial in meeting complex needs.

While in peer learning overall many interventions have applied a broad range of social interdependence elements, at peer tutoring level, as illustrated, this has not always been the case. 
Table 3. Example of coding sheet

\begin{tabular}{|l|l|l|l|l|l|l|l|l|l|l|}
\hline \multicolumn{7}{|c|}{ Mathematics } \\
\hline \\
\hline
\end{tabular}

The areas that teachers, researchers and trainers need to further concentrate on while implementing peer tutoring in order to meet complex social and academic needs are social script interdependence, rewards and goals as set by students and interpersonal communication skills training. As reported in the literature review, most of the metaanalyses of peer tutoring, and peer learning overall, have shown that studies incorporating rewards and goals as set by students and script interdependence provide higher effect sizes on attainment, social and academic variables. Considering that the coding used here did not differentiate between goals and rewards as set by students, which are self-determination elements also advocated by Social Interdependence Theory, the number of peer tutoring papers having implemented these interventions is even smaller, with most of them usually found in the Reciprocal Peer Tutoring approach used by researchers such as Ginsburg-Block and Fantuzzo [5].

Peer tutoring interventions encompassing many of the social interdependence elements would be beneficial to the researchers and policy makers who need to use peer tutoring across a large number of schools, which are more likely to involve complex student needs. Specifically, such interventions would be beneficial if schools needed to improve both the social and academic process of learning elements, as well as academic performance.

\section{Conclusion}

In this paper, we have conducted a methodological review of the extent to which past peer tutoring interventions have applied various social interdependence elements overall, and specifically within three core academic subjects. The research is aimed at helping future teachers, researchers, policymakers and educational research students to identify what has been done and needs to be done in peer tutoring to make more use of the social interdependence characteristics proven to yield large effect sizes.

We found that most peer tutoring interventions do not apply many social interdependence characteristics overall, especially in mathematics and science.

Future research reviews in this area would benefit from taking into account some of the limitations identified in this review.

\section{Acknowledgements}

This is an ESRC funded research, DTC training grant number: ES/I007296/1. Special Thanks to Professor Allen Thurston, Queen's University; and Antje Hornburg.

\section{References}

[1] Abrami, P.C., Chambers, B., Poulsen, C., DeSimone, C., d'Apollonia, S., and Howden, J., Classroom connections - Understanding and using cooperative learning, (1995), Toronto: Harcourt Brace. 
[2] Abrami, P.C., Poulsen, C., and Chambers, B., "Teacher motivation to implement an educational innovation: factors differentiating users and non-users of cooperative learning", Educational Psychology: An International Journal of Experimental Educational Psychology, (2004), 24:2, pp. 201-216.

[3] Chambers, B. "Little ones working together", Journal for Co-operative Studies, (2011), 44(3), pp. 43-48.

[4] Cohen, P.A., Kulik, J.A., and Kulik, C-L.C., "Educational outcomes of tutoring: A Meta-analysis of findings", American Educational Research Journal, (1982), 19, pp. 237-48.

[5] Ginzburg-Block, M., and Fantuzzo, J. (1997). Reciprocal peer tutoring: An analysis of "Teacher" and "Student" interactions as a function of training and experience. School Psychology Quarterly, 12(2), 134-149.

[6] Ginsburg-Block, M., Rohrbeck, D., Cynthia A., and Fantuzzo, J, W., "A meta-analytic review of social, selfconcept, and behavioral outcomes of peer-assisted learning", Journal of Educational Psychology, (2006), 98 (4), Nov, pp. 732-749.

[7] Higgins, S., Katsipataki, M., Coleman, R., Henderson, P., Major, L.E., and Coe, R. (2014). The Sutton TrustEducation Endowment. Sutton Trust.

[8] Johnson, D. W. Reaching Out: Interpersonal Effectiveness and self-actualisation, (1990), Prentice Hall: New Jersey.

[9] Johnson, D.W., and Johnson, R.T. Learning together \& alone: Cooperative, competitive \& individualistic learning, (1987), New Jersey: Prentice-Hall, Inc.

[10] Johnson, D.W., Johnson, R.T., Holubec, E.J., and Roy. P., Circle of Learning: Cooperation in the classroom, (1984), Alexandria, VA: Associations for supervision and Curriculum Development.

[11] Johnson, D. W., Maruyama, G., Johnson, R., Nelson, D., and Skon, L., "The effects of cooperative, competitive, and individualistic goal structures on achievement: A meta-analysis". Psychological Bulletin, (1981), 89, pp. 4762.

[12] Reed, J. G., and Baxter, P. M., "Using reference Databases", in Cooper, H. M., Hedges, L. V., \& Valentine, J. C. (Eds.), Handbook of research synthesis, (2009), Russell Sage Foundation. New York.

[13] Rohrbeck, C. A., Ginsburg-Block, M. D., Fantuzzo, J. W., and Miller, T. R., "Peer-assisted learning interventions with elementary school students: A meta-analytic review", Journal of Educational Psychology, (2003), 95 (1), pp. 240-257.

[14] Roseth, C. J. Johnson, D. W. and Johnson, R.T., "Promoting Early Adolescents Achievement and Peer Relationships: the Effects of Cooperative, Competitive, and Individualistic Goal Structures", Psychological Bulletin, (2008), 134 (2), pp. 223-246.
[15] Slavin, R.E. Co-operative Learning: Theory, Research, and Practice. (2 $2^{\text {nd }}$ edition), (1995), Boston: Allyn and Bacon.

[16] Slavin, R.E. "Co-operative Learning: what makes groupwork Work?", in Dumont H, Istance D, and Benavides F (Eds.), The Nature of Learning: Using Research to Inspire Practice. (pp. 161-178), (2010), Paris, France: OECD.

[17] Topping, K.J., and Ehly, S. (1998). Introduction to peer learning. In Topping, K.J., \& Ehly (Eds.). Peer Assisted Learning. London UK: Lawrence Erlbaum.

[18] Yarrow, F., and Topping, K. J. "Collaborative writing: The effects of metacognitive prompting and structured peer interaction", British Journal of Educational Psychology, (2001), 71, pp. 261-282. 